\title{
O DOCUMENTÁRIO COMO FERRAMENTA DE DIVULGAÇÃO CIENTÍFICA: O QUE DIZEM AS PESQUISAS NA ÁREA DE EDUCAÇÃO EM CIÊNCIAS?
}

\section{Documentaries as a Tool for Scientific Dissemination: What does the Research in Science Education Say?}

\author{
Leandro Siqueira Palcha ${ }^{1}$ \\ Brenno Wendler Miranda ${ }^{2}$ \\ Daniel Nicolas Guimarães Vosch ${ }^{3}$ \\ Tamara Dias Domiciano ${ }^{4}$
}

\begin{abstract}
Resumo: Cada vez mais a Educação em Ciências necessita de alternativas para um aprendizado mais significativo e o cinema de divulgação científica, representado pelos documentários, pode ser um caminho eficiente para isso. O objetivo principal desta pesquisa reside em analisar trabalhos publicados no Encontro Nacional de Pesquisa em Educação em Ciências, no período de 2011 a 2019, estabelecendo o panorama sobre o uso de Documentários de Divulgação Científica no contexto das aulas de Ciências. Em termos metodológicos, realizou-se uma pesquisa bibliográfica e utilizou-se o referencial da Análise de Discurso Francesa para organizar os dados e averiguar as publicações que tratavam do uso deste tipo de mídia no ambiente de ensino em sala de aula. Pôde-se notar que, apesar dos poucos trabalhos tratando desta temática, os documentários de divulgação científica possibilitaram um maior entendimento por parte dos estudantes quanto aos conceitos científicos. Dentre os trabalhos analisados apenas um abordou o Ensino Fundamental, necessitando futuras investigações acerca desta etapa de ensino. Conclui-se que os documentários de divulgação científica, apesar das poucas pesquisas sobre o uso em sala de aula, são recursos promissores para mobilizar o Ensino de Ciências, porém devem ser buscados métodos de ensino que os incluam de forma contextualizada e problematizada às aulas de Ciências, a fim de que os estudantes possam compreender, refletir e divulgar os conhecimentos científicos.
\end{abstract}

Palavras-chave: Análise de discurso. Documentário de divulgação científica. Ensino de Ciências.

\footnotetext{
${ }^{1}$ Doutor e Mestre em Educação pelo Programa de Pós-Graduação em Educação da Universidade Federal do Paraná (UFPR). Graduado em Ciências Biológicas pela UFPR. Professor do Departamento de Teoria e Prática de Ensino, Programa de Pós-Graduação em Educação e Programa de Pós-Graduação em Educação em Ciências e em Matemática da UFPR. ORCID: https://orcid.org/0000-0001-7455-0329). E-mail: leandropalcha@gmail.com

${ }^{2}$ Graduando em Ciências Biológicas na Universidade Federal do Paraná (UFPR). ORCID: https://orcid.org/00000001-6538-5309. E-mail: breeno.miranda@gmail.com

${ }^{3}$ Graduando em Ciências Biológicas na Universidade Federal do Paraná (UFPR). ORCID: https://orcid.org/00000003-4458-9753. E-mail: daniel_vosch@ hotmail.com

${ }^{4}$ Mestra e doutoranda em Educação em Ciências e em Matemática pela Universidade Federal do Paraná (UFPR). Licenciada em Ciências pela UFPR (2016), integrante do Grupo de Pesquisa e Estudos em Alfabetização Científica e Tecnológica (GEPACT-UFPR). ORCID: https://orcid.org/0000-0001-5346-4827. E-mail: tamydomiciano@gmail.com
} 


\begin{abstract}
Increasingly, Science Education needs new alternatives for more meaningful learning. Scientific dissemination cinema, represented by documentaries, can be an efficient way to do this. The main objective of this research is to analyze works published in the National Research Meeting in Science Education, in the period from 2011 to 2019, establishing the panorama on the use of Scientific Dissemination Documentaries in the context of science classes. In methodological terms, bibliographic research was carried out and the French Discourse Analysis framework was used to organize the data and ascertain the publications that dealt with the use of this type of media in the classroom teaching environment. It could be noted that, despite the few papers dealing with this theme, the documentaries of scientific dissemination enabled a greater understanding on the part of the students regarding the scientific concepts. However, only one of the studies analyzed approached Elementary Education, requiring further investigations about this teaching stage. It is concluded that the scientific dissemination documentaries, despite the little research on their use in the classroom, are promising resources to mobilize Science Teaching, however teaching methods that include them in a contextualized and problematized way to science classes should be sought, so that students can understand, reflect, and disseminate scientific knowledge.
\end{abstract}

Keywords: Discourse Analysis. Scientific dissemination documentary; Science teaching.

\title{
1 Introdução
}

Com a chegada ao Brasil em 1896 e com o avanço da tecnologia, o cinema foi gradativamente se tornando um meio acessível e presente na vida diária dos brasileiros (BUENO; SILVA, 2018). Nas salas de exibição nacional, esta expressão artística teve um público de mais de 163 milhões de pessoas em 2018, de acordo com os dados publicados pela Agência Nacional do Cinema (ANCINE, 2018), o que aponta para o interesse da sociedade pelos recursos audiovisuais.

O uso de filmes para a divulgação de conhecimentos científicos também tem sua história. O cinema brasileiro, por exemplo, popularizou-se em meados de 1940 e na época houve uma grande produção de filmes de curta-metragem com a finalidade de divulgar Ciência e Tecnologia. Nesse contexto, destacam-se as obras produzidas pelo Instituto Nacional de Cinema Educativo (INCE), coordenado inicialmente pelo professor, cientista e antropólogo Roquette-Pinto (1884-1954), que utilizaram o cinema para favorecer o processo de ensinoaprendizado. Desde então, a inclusão do cinema na educação passou por inúmeros debates até que foi sancionada a Lei $\mathrm{n}^{\mathrm{o}} 13.006 / 2014$, tornando obrigatório o uso de filmes em escolas (BUENO; SILVA, 2018; OLIVEIRA, 2006).

Ao discorrer sobre o cinema em aulas de Ciências, Santos e Friedrich (2013) argumentam que o uso de filmes pode auxiliar os estudantes no entendimento dos conteúdos ou fenômenos mais difíceis de compreender, aproximar o ensino de outras linguagens e, adentrar na possibilidade de reflexões sobre a produção do conhecimento científico em sala de aula. Dessa maneira, o professor pode promover a curiosidade do estudante, tornando concreto aquilo que é subjetivo no conteúdo de livros didáticos, uma vez que:

[...] a utilização de filmes aparece como veículo de comunicação e de expressão da sensibilidade humana no ambiente escolar. Nesse sentido, o professor pode explorar vários conteúdos, assim como as distorções e as visões tendenciosas apresentadas no enredo da história, que, às vezes, passam despercebidas ao olhar do expectador. 
Assim, o campo de abrangência do audiovisual mostra-se muito diversificado e passível de uma série de encaminhamentos para diferentes áreas (SANTOS; FRIEDRICH, 2013, p. 165).

Observa-se, entretanto, que o ensino de uma forma geral é realizado predominantemente por meio de metodologias expositivas (VASCONCELLOS, 2004). Em linhas gerais, trata-se de aulas conduzidas de forma horizontal, centralizada no professor, na exposição de conteúdos e acríticas, muitas vezes, compostas apenas por quadro e giz, sem abrir espaço para um diálogo sobre o conhecimento produzido entre estudantes e professores.

Na Educação em Ciências, de acordo com Pozo e Crespo (2009), os modelos tradicionais de ensino levam a um declínio do aprendizado dos estudantes e produzem reflexos como: incapacidade de desenvolverem habilidades e, quando têm êxito, não conseguem explicar "o que" e "porquê" aprenderam; resolução de problemas de forma automatizada e repetitiva, buscando apenas os resultados da avaliação. Isso acaba gerando uma perda de sentido e significado do conhecimento científico e conduz os estudantes a um comportamento passivo, desinteressado e com concepções que retratam uma imagem alienada da Ciência que, em suma, é incompatível com a aprendizagem desejável para o século XXI.

A visão mecanizada e esvaziada de reflexão da prática educativa em Ciências, segundo Delizoicov, Angotti e Pernambuco (2018), contribui para a consolidação de um "senso comum pedagógico". Os conteúdos são ministrados de forma isolada e fragmentada da sociedade e as atividades pedagógicas distanciam o educando da contextualização do conhecimento científico à realidade. Desencadeia-se assim, um efeito de "ciência morta", ou seja, uma ciência finalizada, dogmática, e não como uma atividade humana, social e historicamente construída.

Assim, o discurso pedagógico tende a ser um discurso autoritário quando "procura absolutizar um sentido só, de tal maneira que ele não se torne apenas o dominante, mas o único" (ORLANDI, 2013, p. 86). Dito de outra forma, no discurso pedagógico autoritário predomina o ensino expositivo, repetitivo e a construção de significados se estabelece pela ausência de problemas e diálogo entre os locutores.

Faz-se necessário, então, vislumbrar um discurso pedagógico na Educação em Ciências que não se produza como mera transmissão de informação, mas que envolva a interação entre os sujeitos na construção de conhecimentos. Importa conhecer alternativas ao ensino das Ciências voltadas para o diálogo, promovendo uma aprendizagem prazerosa e significativa à vida dos jovens. Como bem observam Santos e Friedrich (2013, p. 168), "nessa confrontação entre o que está se aprendendo em sala de aula e os assuntos econômicos, sociais, políticos e culturais, percebem-se as exigências de um mundo contemporâneo situado em novas formas de linguagem, de tecnologias e de cientificidade".

Em face disso, as metodologias de ensino que envolvem filmes para educação e divulgação científica possuem o potencial de tensionar $o$ discurso do ensino tradicional/autoritário por favorecer o diálogo em sala de aula e aumentar o gosto dos alunos por assuntos envolvendo ciência e tecnologia (LAPRISE; WINRICH, 2010; SURMELI, 2012). Além do mais, fora da sala de aula, filmes também têm o potencial de despertar interesse e preocupações em tópicos como meio ambiente e aquecimento global (LEISEROWITZ, 2004).

O documentário científico, ou documentário de divulgação científica, constitui uma mídia importante para o diálogo entre a sociedade e a comunidade científica (LEÓN, 2008). No entanto, há de se ponderar que os documentários por si só não se constituem em uma forma de representar fielmente a realidade, pois como em todo filme há manipulações (NICHOLS, 2005), podendo ser utilizado para os mais diversos fins. Um exemplo recente é o documentário 
"Vaxxed: from cover-up to catastrophe" (2016) que tem características de um documentário de divulgação científica, mas apresenta informações que destoam do entendimento da comunidade científica acerca de vacinas. Desta forma, é preciso levar em conta as intenções por trás de cada produção, o porquê e para que o filme foi realizado.

Partindo destas considerações e tomando a Análise de Discurso de vertente Francesa (PÊCHEUX, 2012; ORLANDI, 2013) como referencial epistêmico, problematiza-se aqui se as pesquisas na área de Ensino de Ciências têm-se preocupado com a investigação do uso de documentários de divulgação científica como recurso didático no contexto da sala de aula. Com efeito, o objetivo deste artigo reside em analisar como os documentários de divulgação científica (DDC) vêm sendo utilizados em sala de aula, por meio de uma pesquisa bibliográfica na área de Educação em Ciências. Nessa perspectiva, espera-se contribuir para a área, em relação à utilização destes documentários em sala de aula, sobretudo, como uma alternativa à superação do discurso pedagógico autoritário, possibilitando um ensino de Ciências que seja dialógico e promotor da construção de conhecimentos.

\section{Os entrelaçamentos teóricos}

No Brasil, as atividades relacionadas à divulgação científica que concernem, segundo Reis (2002, p. 76), "a veiculação em termos simples da ciência como processo, dos princípios nela estabelecidos, das metodologias que emprega", têm seus primeiros registros no século XVIII e desde então servem a diversos interesses sociais e culturais ao longo da história, nos mais variados formatos e acompanhando a evolução dos meios de comunicação. Nas últimas cinco décadas a divulgação científica tem passado por mudanças quanto à sua prioridade para os cientistas, formas e veículos de divulgação. Nos anos de 1970, por exemplo, houve expressiva adesão da Sociedade Brasileira para o Progresso da Ciência (SBPC) devido à posição ideológica contra a ditadura brasileira e que agregava milhares de pessoas em seus eventos, além de ações desenvolvidas pelo Brasil. Entre os anos 1980 e 1990 foram criados veículos midiáticos de grande circulação social com a finalidade de divulgar a ciência, como as revistas Ciência Hoje e Superinteressante (MOREIRA; MASSARANI, 2002).

Em relação às ações de divulgar a ciência, importa diferenciar divulgação e comunicação científica. Conforme escreve Bueno (2010), uma primeira diferenciação está no público-alvo e intenção das duas práticas: enquanto a comunicação científica visa a difusão do conhecimento intrapares, isto é, de especialista para especialista, a divulgação científica (DC) tem o enfoque no público em geral. Quanto ao discurso, a comunicação pressupõe que seu público está familiarizado com a terminologia ou com os jargões da área, enquanto para a divulgação se faz necessária a decodificação do discurso científico para que este se torne acessível. No entanto, o autor ressalta a possibilidade e o dever de relacionar essas duas categorias da difusão científica, pois a comunicação é fonte para divulgadores e comunicadores da ciência. Desta forma, observa-se que cientistas e jornalistas se encontram como figuras centrais na DC (ZAMBONI, 2001).

A divulgação científica, de forma geral, constitui-se de uma prática social de compartilhamento de conhecimentos científicos por sujeitos de diferentes áreas. Estes sujeitos não pertencem necessariamente à comunidade científica, mas prezam por compartilhar conhecimentos provenientes de fontes seguras, com respaldo científico.

Zamboni (2001) argumenta que a divulgação científica tem um gênero próprio de discurso, pois este deslocará o discurso científico de seus destinatários principais e o difundirá para o público em geral. A autora defende que as produções de DC possuem traços de 
cientificidade, laicidade e didaticidade, em maior ou menor grau. Queiroz e Ferreira (2013) discorrem a respeito destes três termos ao analisarem textos de divulgação científica (TDC):

[...] os traços de cientificidade são aqueles típicos do discurso científico. No entanto, nos TDC, esses traços revelam não apenas aspectos explícitos da práxis científica, mas, também, implícitos (como características pessoais de cientistas, consequências negativas de certos produtos de ciência, entre outros). Ou seja, são marcas de estratégias enunciativas pressupondo um leitor que busca compreender as pesquisas científicas que envolvem a temática do TDC, entender como a ciência é praticada, suas finalidades, a demanda de pesquisas científicas, entre outros. [...] Os traços de laicidade compreendem elementos inerentes ao discurso cotidiano, os quais abarcam as várias formas de contextualização. Traços dessa natureza são evidenciados por meio de recursos discursivos que envolvem a relação da temática científica tratada no TDC com o cotidiano do leitor, portanto, incluem procedimentos de aproximação, simplificação, exemplificação, fórmulas de envolvimento, entre outros. Os traços de didaticidade são próprios do discurso didático, os quais incluem procedimentos como explicações, recapitulações e orientações metodológicas. Neste caso, o enunciador pressupõe um leitor que necessita adquirir certo saber para dar cabo da leitura. Logo, aciona uma série de estratégias com o objetivo de favorecer o entendimento de seu destinatário sobre os aspectos científicos tratados no TDC (QUEIROZ; FERREIRA, 2013, p. 950, grifos nossos).

Cunha e Giordan (2015) assinalam que um texto de divulgação científica sobre um mesmo tópico pode apresentar um discurso diferente dependendo do interlocutor a que se destina, aproximando-se mais dos processos e conhecimentos científicos, em uma esfera, ou mais de situações cotidianas, em outra. Defendem também que o uso de textos de divulgação científica em sala de aula fomenta debates acerca dos tópicos abordados no material, visando os processos da produção do conhecimento científico e tecnológico.

Nessa direção, Kemper (2008) ressalta o papel do professor para a adaptação de materiais de divulgação científica para o contexto da sala de aula, pois simplificações e enganos conceituais podem ser cometidos pelo divulgador. Já sobre a importância da DC na escola, Xavier e Gonçalves (2017) apontam que os recursos de DC têm a vantagem de uma linguagem própria, capaz de estimular a curiosidade dos estudantes acerca da ciência.

Pensada assim, a DC pode materializar-se de diferentes formas, sendo que neste trabalho prioriza-se sua relação com os recursos audiovisuais. Os recursos podem ser definidos como o "conjunto de meios materiais, físicos e humanos que auxiliam o professor e os estudantes na interação do processo ensino-aprendizagem" (SANT'ANNA; SANT'ANNA, 2004, p. 23). O uso de recursos está intimamente relacionado com a história humana e, no que concerne à educação, têm um papel importante, se bem-organizados e utilizados com um propósito, e podem ser considerados os pilares nos quais a construção do conhecimento se ampara (SANT'ANNA; SANT'ANNA, 2004).

Sant'anna e Sant'anna (2004) trazem ainda uma discussão importante sobre a morosidade na apropriação de novas mídias e recursos audiovisuais por parte das escolas, pois a realidade dos estudantes já é composta pela constante exposição a estes estímulos. Neste sentido, os filmes podem representar recursos importantes para a prática docente, pois permitem a compreensão de processos e técnicas, a contextualização de tópicos considerados abstratos, propiciando o ensino de forma prazerosa (SANTOS; FRIEDRICH, 2013). Sendo assim, há a necessidade por parte de estudantes e professores de aprender a ler a mídia cinematográfica e, com essa habilidade desenvolvida, encontrar formas de ensino utilizando os mais diversos gêneros de filmes (ARROIO, 2007). 
Tendo em vista a grande diversidade de materiais audiovisuais, separar um filme do gênero documentário de outras categorias é uma tarefa difícil. Vários autores tentaram estabelecer definições, em relação ao modo de produção do audiovisual, ao objetivo do autor e até mesmo em relação à expectativa dos espectadores (LEÓN, 2007).

Neste aspecto, Nichols (2005) considera que todo filme é um documentário e os documentários podem ser classificados em dois tipos: os documentários de satisfação de desejos, comumente chamados de ficção, e os documentários de representação social, designados de não ficção. É para os filmes de não ficção que Nichols (2005) atribui o termo documentário em seu livro, e mesmo considerando o documentário como "uma representação do mundo em que vivemos", afirma que não há uma definição completa e absoluta desta palavra, pois ela se dá de maneira relativa, ocorre em contraste com outros gêneros fílmicos e muda com o tempo.

Entendendo que todo filme pode ser um documentário e que não há uma definição absoluta deste gênero, passa-se então a discutir sobre o tipo de documentário a que este trabalho se refere, os documentários de não ficção. Para auxiliar na compreensão do gênero, Nichols (2005) apresenta quatro abordagens que facilitam na determinação de uma produção como documentário. A primeira diz respeito à estrutura institucional, a qual organizações e produtoras de audiovisual ditam se determinada obra é um documentário. Uma outra abordagem considera que a definição de documentário é formada pelos próprios documentaristas e é a partir do trabalho e das ideias destes profissionais que a compreensão deste gênero é construída e sujeita a mudanças.

A terceira abordagem tratada por Nichols (2005), utiliza elementos encontrados no corpus de textos em filmes já classificados como documentários para definir este gênero. Desta maneira, para que uma obra seja classificada como documentário, ela deve apresentar as normas e convenções comuns a este gênero. Dentre estas, pode-se citar os comentários "voz de deus", o uso de entrevistas e técnicas de filmagem e edição características destes filmes. Também pode ser levado em conta a organização do filme segundo uma "lógica informativa". No entanto, apesar de procurar retratar a realidade, o gênero é dinâmico e não permanece inalterado ao longo do tempo, passando por transformações em estilos, modos e tendências de produção, podendo não ser intuitiva a definição de um filme documentário segundo estes critérios. Melo (2002, p. 26) afirma que "o que parece permanecer sempre como característica fundamental do documentário é o fato de ser um discurso pessoal de um evento que prioriza exigências mínimas de verossimilhança, literalidade e o registro in loco".

A última abordagem de Nichols (2005) traz os espectadores como agentes responsáveis pela formação desse conceito, por meio de suas expectativas, ideias e interpretações a respeito do filme, considerando que o público se envolve de uma maneira distinta de outros gêneros fílmicos. Este envolvimento traz um desejo de aprendizado e provoca questionamentos a respeito do mundo histórico e o papel do observador dentro dele. É nesta abordagem que se ancora a busca de trabalhos para esta pesquisa, levando em conta o que os autores dos textos consideraram como documentário para suas metodologias.

Como os documentários, uma definição de documentário de divulgação científica (DDC) é uma tarefa difícil de ser realizada, porém existem duas situações em que se encontra uma correlação nítida entre o conteúdo do documentário e a ciência. Em uma delas, há a abordagem e o desenvolvimento de tópicos que constituem um objeto de estudo de uma área da ciência. Na outra, a exibição de recursos audiovisuais que serviram como ferramentas de estudo para pesquisadores, como imagens ou sons, e que auxiliam no entendimento público do conhecimento científico (LEÓN, 2007; 2008). Neste trabalho, entende-se por DDC os 
documentários que se enquadram em pelo menos uma destas situações e que apresentam os traços característicos do discurso da DC, evidenciados por Zamboni (2001).

Os documentários têm um lugar privilegiado em sala de aula, pois representam uma aparente realidade e o uso de técnicas de produção, como a inserção de falas de especialistas em um assunto, que os tornam mais dignos de crédito (BRUZZO, 1998; VIEIRA; MARTINS, 2017). Um exemplo da credibilidade que é dada aos documentários é encontrado na pesquisa de Passau et al. (2011), realizada em 2009, a qual constatou que filmes científicos ou documentários científicos foram usados por $62 \%$ dos docentes em sala de aula.

As aplicações dos DDC em sala de aula já propiciaram experiências positivas para a Educação em Ciências (CAMARGO; BARBARÁ; BERTOLDO, 2008; GUEDES; REIS; JOUCOSKI, 2017). Desta forma, investigar as potencialidades de novos gêneros discursivos em sala de aula, seja o do cinema, seja o da DC, ou então da combinação destes dois, é uma oportunidade para a reflexão da prática docente, já que é essencial, desde a formação, saber articular a pesquisa e ensino, como uma forma construtiva e criativa para ensinar Ciências (CARVALHO; GIL-PÉREZ, 2011).

Dito tudo isso, enfatiza-se um dos conceitos centrais deste trabalho: o discurso pedagógico. O referencial epistêmico da Análise de Discurso de vertente francesa vem sendo desenvolvido desde os anos 1960, na França, pelos estudos do filósofo da linguagem Michel Pêcheux e, no Brasil, pela professora Eni Orlandi. Filiados a esta perspectiva, define-se que "o discurso é o efeito de sentido entre locutores" (ORLANDI, 2013, p. 21). Portanto, seu estudo visa desnaturalizar a transparência da linguagem, demonstrando que os dizeres são sempre construídos por meio de condições de produção numa determinada conjuntura social, histórica e ideológica.

Para Orlandi (2011), a produção da linguagem se dá na articulação de dois grandes processos: o parafrástico e o polissêmico.

\begin{abstract}
Isto é, de um lado, há um retorno constante a um mesmo dizer sedimentado - a paráfrase - e, de outro, há no texto uma tensão que aponta para o rompimento. Esta é uma manifestação da relação entre o homem e o mundo (a natureza, a sociedade, o outro), manifestação da prática e do referente na linguagem. Há um conflito entre o que é garantido e o que tem de se garantir. A polissemia é essa força na linguagem que desloca o mesmo, o garantido, o sedimentado. Essa é a tensão básica do discurso, tensão entre o texto e o contexto histórico-social: o conflito entre o 'mesmo' e o 'diferente', entre paráfrase e polissemia (ORLANDI, 2011, p. 27).
\end{abstract}

Em outras palavras, a mobilização de sentidos pode ocorrer apenas repetindo e transmitindo o que já se sabe ou, ainda, pode-se pensar na produção e circulação de outros sentidos, como uma possibilidade de construção de conhecimento. Neste estudo, advoga-se a favor de um processo de ensino-aprendizagem em Ciências para além de uma tradição discursiva de transmissão de conhecimento (como ocorre nas metodologias de ensino expositivas), ou seja, impõe-se considerar o discurso pedagógico numa perspectiva construtiva, vale dizer, menos repetitiva e mais dialógica.

Dessa forma, pode-se caracterizar três tipos de discurso, a saber: o discurso autoritário, o discurso polêmico e o discurso lúdico. 
a) Discurso autoritário: aquele em que a polissemia é contida, o referente está apagado pela relação de linguagem que se estabelece e o locutor se coloca como agente exclusivo, apagando também sua relação com o interlocutor;

b) Discurso polêmico: aquele em que a polissemia é controlada, o referente é disputado pelos interlocutores, e estes se mantêm em presença, numa relação tensa de disputa pelos sentidos;

c) Discurso lúdico: aquele em que a polissemia está aberta, o referente está presente como tal, sendo que os interlocutores se expõem aos efeitos dessa presença inteiramente não regulando sua relação com os sentidos (ORLANDI, 2013, p. 86).

Na perspectiva de Orlandi (2011), o discurso pedagógico tende a ser autoritário quando incorpora uma perspectiva impositiva, parafrástica, repetitiva, predomina a transmissão de conhecimentos pouco interativa entre os sujeitos. No discurso pedagógico autoritário o professor, enquanto transmissor de conhecimentos, é o centro das atenções, detentor da palavra e consequentemente da produção de sentidos. Ao estudante cabe o silêncio, memorização e repetição dos conteúdos que lhe serão cobrados em uma avaliação e logo então esquecidos.

No caminho inverso ao autoritarismo, defende-se aqui um discurso pedagógico numa perspectiva participativa, que envolva a produção de diferentes sentidos e o diálogo entre os sujeitos e os conhecimentos em sala de aula. Nessa medida, o discurso polêmico (ORLANDI, 2011) abre margens para participação dos estudantes, para inclusão de outras propostas de ensino, como no caso das metodologias envolvendo a divulgação científica e o uso dos documentários.

\section{Metodologia da pesquisa}

Esta pesquisa, de natureza qualitativa e de cunho bibliográfico, foi desenvolvida durante o ano de 2020, e é um recorte de um projeto maior. A pesquisa bibliográfica se baseia na literatura para compilar, discutir e avaliar as informações presentes em diferentes publicações acadêmicas sobre o tema a ser investigado e analisar estas produções de acordo com o contexto na qual elas se inserem (GIL, 2010).

Optou-se assim por um levantamento e sistematização de trabalhos apresentados no Encontro Nacional de Pesquisa em Educação em Ciências (ENPEC), um dos principais eventos da área de Ensino de Ciências e que reúne pesquisadores de todo o país. Este evento ocorre a cada dois anos, promovido pela Associação Brasileira de Pesquisa em Educação em Ciências (ABRAPEC). As consultas se deram nas atas da última década, ou seja, das últimas cinco edições $(2011,2013,2015,2017,2019)$ publicadas no site da ABRAPEC. A escolha por este banco de dados se justifica em função de não restringir a participação de profissionais da educação, envolvendo trabalhos de graduação, pós-graduação e professores da Educação Básica, o que permitiria atingir o objetivo deste trabalho ao dar uma visão mais próxima da sala de aula.

No site de cada evento, pesquisou-se nas atas os trabalhos que continham os termos "filme(s)", "cinema", "documentário(s)" e/ou "audiovisual(is)" em seus títulos ou palavraschave. Após, realizou-se a leitura dos resumos dos trabalhos e os artigos que abordavam filmes do gênero documentário foram selecionados. Caso não fosse explícita a categorização de um filme como pertencente ao gênero documentário pelos autores ao longo do texto, o trabalho seria descartado. Por serem documentários de relativo acesso, assistiram-se às produções mencionadas nos artigos, a fim de examinar se elas pertenciam ao gênero da divulgação científica e se deviam ser incluídas ao corpus de análise. Por documentário de divulgação científica reitera-se aqui a definição de León $(2007$; 2008), a qual diz que estes documentários 
focam em resultados de pesquisas ou conhecimentos relativos a uma área da ciência ou têm a participação explícita de cientistas ou instituições em sua elaboração. Além disso, procurou-se identificar traços característicos de discursos de Divulgação Científica, assim como definidos por Zamboni (2001), a cientificidade, a laicidade e a didaticidade. As exceções foram justificadas nos resultados. O escopo ainda foi delineado apenas pelos trabalhos que envolviam a exibição ou produção de DDCs na Educação Básica.

Portanto, o corpus de análise se constitui pelos seguintes critérios:

a) Critérios de inclusão: artigos de pesquisa publicados entre 2011 e 2019 nas atas do ENPEC que envolvem a exibição ou produção de DDCs na Educação Básica;

b) Critérios de exclusão: artigos de pesquisa não publicados entre 2011 e 2019 nas atas do ENPEC ou que não envolvem a exibição ou produção de DDCs na Educação Básica.

Os artigos selecionados para análise, com base nos critérios de inclusão, foram então organizados em uma planilha de dados, contendo o ano de publicação, autores, títulos, objetivos, metodologias e principais resultados. A leitura dos artigos foi realizada buscando verossimilhanças nos textos, que foram então agrupados em abordagens para seu uso nas discussões.

Como já foi explicitado, este trabalho filia-se ao referencial epistêmico da Análise de Discurso Francesa (ORLANDI, 2013). Assim, os procedimentos da análise têm como central a noção de funcionamento do discurso, levando o analista a compreender os processos de constituição de sentidos. Portanto, as etapas tomadas para a análise promovem um percurso de passagem da leitura do texto (superfície linguística) ao discurso (processo discursivo), no contato com o corpus que fora constituído.

\section{Resultados e discussões}

De forma geral, a pesquisa encontrou 16 trabalhos publicados nas atas do ENPEC entre os anos 2011 e 2019 que abordam filmes do gênero documentário, explicitados pelos autores. Destes, metade não envolviam a exibição ou produção de documentários na Educação Básica, realizando apenas reflexões sobre estas mídias no ensino ou abordando contextos que não são englobados pela Educação Básica, de forma que apenas oito foram selecionados segundo os critérios de inclusão (Tabela 1).

Tabela 1 - Números de trabalhos encontrados nas atas do ENPEC

\begin{tabular}{c|r|r|r|c}
\hline \multicolumn{1}{c|}{ Ano } & Encontrados & Documentário & DDC & DDC em sala de aula \\
\hline 2011 & 21 & 4 & 2 & 2 \\
2013 & 11 & 3 & 3 & 2 \\
2015 & 20 & 4 & 3 & 2 \\
2017 & 18 & 3 & 1 & 1 \\
2019 & 13 & 2 & 1 & 1 \\
TOTAL & 83 & 16 & 10 & 8 \\
\hline
\end{tabular}

Fonte: Os autores (2020).

Os resultados serão apresentados por meio da noção discursiva chamada recorte, ou seja, "unidade discursiva: fragmento correlacionado de linguagem - e-situação" (ORLANDI, 2011, p. 139) que remete à organização do todo. Os três recortes foram organizados pelos anos que ocorreram o evento durante a última década. 
4.1 Recorte 1: os dizeres das pesquisas publicadas em 2019 e 2017

Dos 31 artigos encontrados em 2019 e 2017, apenas dois trabalhos enquadraram-se nos critérios de inclusão e foram inseridos no corpus de análise, conforme Quadro 1.

Quadro 1 - Artigos publicados nas atas do ENPEC de 2019 e 2017

\begin{tabular}{|l|l|l|l|}
\hline AUTORES & ANO & \multicolumn{1}{|c|}{ TÍTULO } & \multicolumn{1}{c|}{ PALAVRAS-CHAVE } \\
\hline $\begin{array}{l}\text { Daniela } \\
\text { Frey }\end{array}$ & 2019 & $\begin{array}{l}\text { "O Despertar de uma Paixão" e o } \\
\text { ensino de cólera e evolução. }\end{array}$ & $\begin{array}{l}\text { O despertar de uma paixão, filme como } \\
\text { estratégia de ensino, ensino de cólera, John } \\
\text { Snow, ensino de evolução. }\end{array}$ \\
\hline $\begin{array}{l}\text { Pereira } \text { et } \\
\text { al. }\end{array}$ & 2017 & $\begin{array}{l}\text { O estudo da Energia com enfoque } \\
\text { CTS, fundamentado no } \\
\text { documentário Power. }\end{array}$ & Energia, ciência, tecnologia, sociedade. \\
\hline
\end{tabular}

Fonte: Os autores (2020).

O trabalho de Pereira et al. (2017) investigou o uso do documentário "Power" em uma abordagem Ciência-Tecnologia-Sociedade (CTS) para o tema da produção de energia. Os autores aplicaram questionários a fim de identificar a compreensão dos estudantes do terceiro ano do Ensino Médio acerca do tema antes e após a intervenção, e notaram diferenças nas respostas dos questionários após a exibição do filme. Mesmo com a visão da maioria dos estudantes limitando-se apenas às implicações econômicas do tema, possivelmente em decorrência do enfoque político e econômico da obra, o uso deste recurso audiovisual possibilitou a associação das questões relativas à energia com o cotidiano dos estudantes e uma ampliação de suas percepções sobre o assunto.

A pesquisa de Frey (2019), com alunos do Ensino Médio, investigou a utilização de filmes como estratégia para o ensino de doenças infectocontagiosas. Assim, foi elaborado um questionário inicial para os discentes e os dados foram organizados em padrões de respostas. Após o questionário, o filme $O$ Despertar de uma Paixão, que trata de uma epidemia de cólera, foi exibido e seguido de um brainstorm e debate acerca da obra. Na etapa seguinte, foram exibidos trechos do documentário A Corrida das Espécies, associando aspectos da evolução biológica com diversas doenças, incluindo a cólera. Por último, o questionário foi novamente aplicado para a comparação das respostas. A autora notou que as respostas em branco, as que os estudantes não souberam responder ou que não tinham correlação com a pergunta diminuíram no último questionário, e mesmo com alguns estudantes persistindo com as suas concepções prévias, o padrão de respostas que evidencia o desenvolvimento de conceitos correlacionados às perguntas realizadas aumentou no final do estudo.

O artigo de Frey (2019) ao incluir debates e brainstorms a respeito dos audiovisuais e não apenas utilizá-los de maneira expositiva, demonstra um desejo de ruptura com o discurso autoritário. Mediante o não-dito, repara-se a dificuldade do ensino de evolução, tema ainda controverso no contexto da educação (MEDEIROS; MAIA, 2013), que se revela com a persistência de alguns conceitos prévios dos estudantes. Já pelo trabalho de Pereira e colaboradores (2017), nota-se que o ensino da temática produção de energia é tradicionalmente pensado em termos econômicos, no qual a ciência tem a função de resolver problemas ligados ao capital. Em termos gerais, a partir das ideias defendidas por Cunha e Giordan (2015) acerca de materiais de DC em sala de aula, vê-se que apesar do notável progresso na construção do conhecimento científico dos estudantes com o auxílio dos DDCs, faz-se necessária uma mediação didática do professor que ofereça discussões críticas sobre os conteúdos apresentados nestas obras, contribuindo assim para o sucesso da aplicação de recursos de DC no ensino de Ciências. 
4.2 Recorte 2: os dizeres das pesquisas publicadas em 2015 e 2013

Em relação aos eventos dos anos 2015 e 2013 foram encontrados 30 trabalhos e quatro destes tratavam de DDC em sala de aula (Quadro 2).

Quadro 2 - Artigos publicados nas atas do ENPEC de 2015 e 2013

\begin{tabular}{|l|l|l|l|}
\hline \multicolumn{1}{|c|}{ AUTORES } & ANO & \multicolumn{1}{|c|}{ TÍTULO } & \multicolumn{1}{c|}{ PALAVRAS-CHAVE } \\
\hline $\begin{array}{l}\text { Vieira e } \\
\text { Ramos }\end{array}$ & 2015 & $\begin{array}{l}\text { Representações de invertebrados em aulas } \\
\text { de Biologia. }\end{array}$ & $\begin{array}{l}\text { Ensino de invertebrado, audiovisual, } \\
\text { estudos culturais. }\end{array}$ \\
\hline $\begin{array}{l}\text { Cazón e } \\
\text { Oliveira }\end{array}$ & 2015 & $\begin{array}{l}\text { Produção de documentário científico e as } \\
\text { Relações com o Saber. }\end{array}$ & $\begin{array}{l}\text { Análise de discurso, autoria, ensino } \\
\text { de biologia. }\end{array}$ \\
\hline $\begin{array}{l}\text { Santos e } \\
\text { Gebara }\end{array}$ & 2013 & $\begin{array}{l}\text { Cinema como recurso didático: motivação } \\
\text { nas aulas de ensino de ciências. }\end{array}$ & $\begin{array}{l}\text { Ensino de Ciências, Aprendizagem, } \\
\text { Cinema, Recurso didático, Educação } \\
\text { Básica, Ecologia. }\end{array}$ \\
\hline $\begin{array}{l}\text { Cruz e } \\
\text { Fernandes }\end{array}$ & 2013 & $\begin{array}{l}\text { Limites e possibilidades sobre o uso do } \\
\text { vídeo documentário científico no ensino de } \\
\text { Física. }\end{array}$ & $\begin{array}{l}\text { Vídeo documentário, ensino de } \\
\text { Física, momentos pedagógicos. }\end{array}$ \\
\hline
\end{tabular}

Fonte: Os autores (2020).

O trabalho de Vieira e Ramos (2015), a partir dos Estudos Culturais, investigou os sentidos que estudantes do Ensino Médio têm acerca de invertebrados, que normalmente recebem uma representação depreciativa da sociedade. A pesquisa aborda modos diferentes de trabalhar e retratar os invertebrados na sala de aula de uma maneira mais positiva. Entre estas abordagens, houve a exibição de um trecho do documentário MICROCOSMOS - Le Peuple de L'herbe (1996), que retrata o ritual de acasalamento de dois caracóis de uma maneira romantizada, pois parecem estar se beijando e há música clássica tocando ao fundo. Eles analisaram audiovisuais desenvolvidos pelos estudantes e que tinham os invertebrados como tema principal, sendo nítida a presença e persistência das imagens pejorativas dos invertebrados pelos educandos. Os autores observaram também uma dificuldade dos estudantes ao retratar os invertebrados em seus audiovisuais, raramente fugindo dos conteúdos presentes no livro didático, ou seja, de uma maneira conteudista. Terminam por ressaltar a importância de trazer novas narrativas e representações dos invertebrados na sala de aula, para que os estudantes possam ampliar as suas visões e conhecimentos, construindo assim a sua identidade.

Cazón e Oliveira (2015) fizeram uma conexão entre a teoria da Relação com o Saber, proposta pelo autor francês Bernard Charlot, e a Análise de Discurso Francesa, utilizando estes referenciais para examinar a mobilização de estudantes do último ano do Ensino Médio, ao produzirem um documentário para o componente curricular Biologia. Analisando a trajetória dos educandos durante a estratégia metodológica e os trechos do documentário produzido pelos estudantes Anomalias Cromossômicas: um Olhar sobre a Síndrome de Down, os autores formularam três eixos: o dos dispositivos teóricos; o do interdiscurso; e o da relação com o saber, sendo que os dois primeiros são provenientes da AD. Os eixos auxiliam a visualizar a correlação entre os três componentes utilizados na análise. Cazón e Oliveira (2015) conseguiram aproximar características dos discursos e a relação dos estudantes com o saber e constatam que, apesar de difícil, a aproximação dos conhecimentos destas duas áreas é possível e pode ser utilizada para examinar como ocorre a construção do saber.

Em termos de análise dos trabalhos referentes às aulas de Biologia, nota-se que o foco do trabalho de Vieira e Ramos (2015) está na percepção dos estudantes em relação aos invertebrados. Os estudantes tiveram a liberdade de aproximar o conteúdo da sua vivência por meio da produção de paródias e vídeos nos quais, apesar das dificuldades em romper com o 
ensino tradicional/autoritário, exibiram as suas visões sobre os invertebrados, construindo sentidos sobre o assunto em questão e aumentando a motivação para o estudo. Já pelo que foi exposto por Cazón e Oliveira (2015), percebe-se que os DDCs podem ser produzidos na Educação Básica e essa produção permite a construção ativa do conhecimento, colocando os estudantes como protagonistas da aprendizagem. Os estudantes tiveram a oportunidade de entrevistar pesquisadores da área que escolheram, o que propicia a desmistificação da imagem do cientista, ao mesmo tempo em que aproxima os discentes do meio científico e da universidade, que muitas vezes parece estar distante.

Até aqui, coadunando com Arroio (2007), percebe-se uma necessidade urgente na formação do professor para um letramento a respeito do uso de recursos cinematográficos em sala de aula. A confecção de audiovisuais possibilita não somente a construção do conhecimento sobre o assunto que está sendo trabalhado, mas também a familiaridade com recursos tecnológicos e a linguagem artística, permitindo a aproximação do estudante com o objeto de conhecimento e a realidade, desta forma aumentando o sucesso do aprendizado (VASCONCELLOS, 2004).

Por conseguinte, Santos e Gebara (2013) pesquisaram sobre a utilização de filmes de diferentes gêneros cinematográficos como recursos didáticos adequados para o uso no Ensino de Ciências. Para isso foi realizada uma sequência didática com a temática Ecologia, para o nono ano do Ensino Fundamental de uma escola pública no Paraná, utilizando filmes de animação, educativos e documentários; foi também elaborado um portfólio para a coleta de dados, registrando continuamente as atividades desenvolvidas. Entre os filmes se encontram três documentários: Lixo Extraordinário, que retrata a vida no aterro do Jardim Gramacho, e discorre sobre a importância da reciclagem; Ilha das Flores, que evidencia desigualdades sociais ao acompanhar o percurso de um simples tomate, da sua colheita até o aterro; e o documentário animado História das Coisas, que critica o consumismo e expõe práticas que acontecem na produção de bens materiais. Os autores relataram uma contribuição positiva do cinema no aprendizado e na educação científica e ressaltaram a importância do professor como mediador na identificação e relação da imagem cinematográfica e conhecimento.

Cruz e Fernandes (2013) analisaram a potencialidade do uso de um documentário científico no ensino de Física. A pesquisa foi realizada com estudantes do segundo ano do Ensino Médio, em um colégio da cidade de Ubaitaba-BA, e buscaram desenvolver o assunto "Dilatação dos Sólidos e Líquidos e Expansão dos Gases" através do documentário O Zero Absoluto - A Conquista do Frio, desenvolvendo uma proposta de ensino, tendo como base os "Três Momentos Pedagógicos" (DELIZOICOV; ANGOTTI; PERNAMBUCO, 2018), com a distribuição de questionários acerca do conteúdo em um primeiro momento, a exibição do documentário em outro, e a distribuição de novos questionários no terceiro momento. Com esta metodologia foram capazes de constatar, a partir da comparação entre os momentos pedagógicos, a construção e mudança de conceitos nos educandos após a exibição do audiovisual, as influências da obra nas respostas do questionário, que se aproximaram de conceitos científicos, e uma redução nas dúvidas e na dispersão dos estudantes.

Para as aulas de Ciências, como aduz o trabalho de Santos e Gebara (2013), o ensino de Ecologia no Fundamental II necessita de metodologias contrastantes ao ensino tradicional/autoritário. De acordo com resultados obtidos pelos autores vê-se a importância do cinema em sala de aula, pois auxiliou no processo de aprendizado por ilustrar situações e criar laços entre estudantes e os conteúdos, característica que a aula realizada nos moldes convencionais não permite. Pode-se considerar que a inserção de documentários em sala de aula propicia uma visão socioeconômica da Ecologia, como foi visto na fala de um estudante participante da pesquisa. 
Dito de outra forma, o recurso cinematográfico contribuiu no ensino de Ecologia, pois, corroborando com as considerações de Santos e Friedrich (2013), o cinema é capaz de ilustrar e aproximar conceitos abstratos para o contexto da sala de aula. Além disso, propicia a conciliação do conteúdo escolar com a contribuição social da ciência.

No ensino de Física, Cruz e Fernandes (2013) utilizaram questionários antes e após a exibição do documentário para avaliar o desempenho dos estudantes em relação à estratégia pedagógica analisada. Porém, nota-se que esta abordagem apresenta alguns entraves em se distanciar do ensino tradicional, pois apenas metade das questões expostas aos educandos eram problematizadoras e o professor atuava em conjunto com o audiovisual acrescentando conceitos. Observa-se que a avaliação das respostas se deu conforme a sua concordância com o consenso científico, o que seria menos provável no primeiro momento.

Nesta abordagem, observa-se que o documentário de fato auxilia a compreensão de processos e fenômenos naturais, porém a mera exposição de um recurso audiovisual não é o suficiente para quebrar os paradigmas da educação tradicional/autoritária. Em concordância com Ferreira e Queiroz (2015), os recursos de DC podem ser aliados de um aprendizado crítico, pois propiciam a abertura para um discurso polêmico em sala de aula.

4.3 Recorte 3: os dizeres das pesquisas publicadas em 2011

Os trabalhos analisados das atas de 2011 estão representados no Quadro 3.

Quadro 3 - Artigos publicados nas atas do ENPEC de 2011

\begin{tabular}{|l|l|l|l|}
\hline \multicolumn{1}{|c|}{ AUTORES } & ANO & \multicolumn{1}{|c|}{ TÍTULO } & PALAVRAS-CHAVE \\
\hline Silva e Frenedozo & 2011 & $\begin{array}{l}\text { A utilização de filmes na mediação da } \\
\text { aprendizagem de temas sobre a aplicação do } \\
\text { conhecimento genético no ensino de Biologia. }\end{array}$ & $\begin{array}{l}\text { Ensino de Biologia, } \\
\text { Filmes, Temas polêmicos. }\end{array}$ \\
\hline $\begin{array}{l}\text { Couto e Rezende } \\
\text { Filho }\end{array}$ & 2011 & $\begin{array}{l}\text { Documentário de Divulgação Científica em tempos } \\
\text { de redes sociais e cibercultura. }\end{array}$ & $\begin{array}{l}\text { Documentário, divulgação } \\
\text { científica, senso comum, } \\
\text { celular. }\end{array}$ \\
\hline
\end{tabular}

Fonte: Os autores (2020).

Biotecnologia, clonagem, o genoma humano, células-tronco e geneterapia são assuntos relativamente polêmicos em aulas de Biologia, e o uso de filmes para auxiliar no ensino destes conteúdos é analisado no trabalho de Silva e Frenedozo (2011). A pesquisa, realizada com estudantes do segundo ano do Ensino Médio, teve primeiramente como metodologia aulas teóricas a respeito da genética, em seguida os estudantes realizaram uma pesquisa bibliográfica sobre os assuntos, pois eles eram escassos nos livros didáticos, e por último houve a exibição dos filmes acompanhada de uma discussão, relatórios ou questionários acerca da obra assistida e o tema abordado. Dentre as obras trabalhadas estavam o primeiro e segundo episódio do documentário DNA: A Promessa e o Preço, que evidencia avanços genéticos como a geneterapia e o estudo de células-tronco, e expõe as suas possíveis implicações e consequências. Os pesquisadores aplicaram um questionário após a exibição das obras, e os estudantes afirmaram, através de uma questão de múltipla escolha, que os filmes contribuíram para ampliar a compreensão dos conteúdos e seus contextos nas aulas de Biologia, uma vez que se aproximam da realidade. 
O trabalho de Couto e Rezende Filho (2011) explora os elementos do vídeo Documentário - Um olhar sobre a Vila Velha, buscando responder à pergunta: este audiovisual pode ser considerado um documentário para a divulgação científica? A obra, apresentada no "3 Simpósio Hipertexto e Tecnologias na Educação: redes sociais e aprendizagem”, em dezembro de 2010, foi produzida por estudantes e professores de uma escola municipal na cidade de Itapissuma-PE utilizando somente a câmera de um celular e simples edições de vídeo. A obra em questão relata, a partir de uma entrevista realizada pelos estudantes com uma moradora da região, os problemas ambientais, políticos, sociais e econômicos dos moradores de uma pequena comunidade próxima da escola, chamada de Vila Velha, e entre as dificuldades enfrentadas está a poluição, pesca predatória de grande porte, a falta de saneamento, infraestrutura e coleta de lixo na região. Os pesquisadores tiveram como referencial $\mathrm{Um}$ Discurso sobre as Ciências, de Boaventura de Souza Santos, e evidenciaram que no vídeo analisado há elementos que estão presentes em filmes e vídeos para divulgação científica contemporâneos. Os autores enfatizam o processo de desenvolvimento deste audiovisual, no qual os docentes e discentes tornaram-se sujeitos da experiência, participantes dos debates e da sabedoria popular da comunidade, neste sentido destaca-se o potencial das tecnologias de informação.

Ante o exposto, analisando o trabalho de Silva e Frenedozo (2011), percebe-se que o ensino de temas considerados controversos não dialoga com o discurso autoritário presentes em muitas salas de aula. Faz-se necessária a polemização do conteúdo, permitindo a ampla participação dos estudantes nas discussões a fim de desmistificar visões equivocadas acerca da ciência e dos temas em questão. O uso de DDCs e outros recursos de DC são importantes para a contribuição destas discussões, pois apresentam informações que não estão presentes em livros didáticos, por exemplo, e auxiliam na ampliação de ideias para o debate.

Semelhante aos trabalhos de Cazón e Oliveira (2015), e Vieira e Ramos (2015), a pesquisa de Couto e Rezende Filho (2011) explorou a produção de um audiovisual na Educação em Ciências. Na produção do documentário em questão, os estudantes e professores não se limitaram simplesmente às questões ambientais: colocaram-se como sujeitos daquela comunidade, seja por meio da coleta voluntária de lixo apresentada no filme, ou pela entrevista com a moradora. Em termos de análise, neste artigo é possível observar novamente que a mediação de uma abordagem na qual os estudantes se encontram como sujeitos autores faz-se uma possibilidade para tensionar o método de ensino expositivo/autoritário e que pode favorecer um aprendizado engajador e significativo para os educandos, ao mesmo tempo em que estabelece uma conexão direta entre a ciência, a tecnologia e a sociedade.

Em suma, tem-se que a DC pode fomentar o debate de temas polêmicos, pois, em consonância com Kemper (2008), é uma forma de levar para a sala de aula o que há de mais recente no meio científico e os professores têm papel fundamental na escolha e mediação do que e como será utilizado. Em tópicos controversos é importante que conteúdos atualizados sejam tratados em sala de aula, pois avanços são realizados constantemente e novas descobertas podem contribuir para a discussão e a construção de conhecimentos não apenas de questões científicas, mas também éticas e sociais.

\subsection{Articulando os discursos}

Uma tendência observada nos trabalhos é a constatação da potencialidade dos DDCs como recursos no Ensino de Ciências, pois auxiliam na construção de conceitos e sentidos e nos casos em que há produção de audiovisuais, como no trabalho de Cazón e Oliveira (2015). Neste, os estudantes se envolveram de forma engajadora, colocando-se no papel de 
protagonistas e autores, possibilitando também a contextualização do tema e aumentando o repertório científico dos educandos.

Na perspectiva dos autores, a liberdade de escolha dos temas pelos estudantes favorece o desenvolvimento da motivação intrínseca, que segundo Santrock $(2009$, p. 454) "envolve a motivação para realizar algo em si mesmo (o fim em si mesmo)", uma vez que são livres para selecionar os assuntos que mais se interessam. Isto é evidenciado pela provável relação entre a escolha do tema do documentário e a vivência pessoal de um dos estudantes-autores, que teve problemas de saúde durante a infância. Esta motivação, quando aparece no contexto escolar, contribui de uma maneira mais significativa para o processo de ensino-aprendizagem que a motivação extrínseca, que envolve estímulos e incentivos externos e normalmente trata o aprendizado como um meio para um fim (SANTROCK, 2009). O artigo de Vieira e Ramos (2015) destaca-se pela sua abordagem diferenciada na sala de aula, utilizando o DDC e outros recursos para apresentar uma visão enaltecedora dos invertebrados, que é contrária à imagem pejorativa que estes geralmente têm. A partir de sua abordagem distinta, a pesquisa trouxe novas ideias ao Ensino de Ciências. No entanto, o documentário exibido neste trabalho ressalta um elemento comum a algumas obras deste gênero, que é a antropomorfização dos animais (BORBA, 2017), e essa tendência também foi observada na subsequente produção de audiovisuais pelos estudantes.

Os resultados das pesquisas corroboram o que Sant'Anna e Sant'Anna (2004) argumentaram acerca do uso de recursos audiovisuais em sala de aula, pois nota-se que os filmes permitiram uma maior compreensão dos conteúdos abordados e facilitaram a aproximação dos estudantes aos conceitos científicos tratados pelos filmes.

A DC se mostrou uma aliada à problematização do ensino, pois, mesmo em trabalhos que adotaram uma metodologia expositiva do audiovisual, foi possível observar um resultado positivo acerca de desestabilizar o senso comum em relação aos conteúdos científicos. Além disso, observou-se que o uso do DDC também pode propiciar a aproximação da realidade do estudante e o conteúdo, trazendo assim um aprendizado mais significativo, como observado no trabalho de Cazón e Oliveira (2015) e Couto e Rezende Filho (2011); e apresentar percepções desafiadoras e não convencionais do mundo, como na representação dos invertebrados no trabalho de Vieira e Ramos (2015). Desta maneira, a conciliação adequada entre estas obras, que utilizam a linguagem da DC, e a sala de aula pode contribuir para diminuir o autoritarismo no ambiente de ensino e caminhar para uma visão construtivista do ensino de Ciências, tendo o potencial de superar alguns dos problemas na educação tradicional/expositiva expostos por Vasconcellos (2004).

Porém, é importante atentar que a falta desta conciliação pode levar para o uso dos audiovisuais de maneira exclusivamente expositiva e sem a devida mediação, caracterizando uma metodologia chamada por Vasconcellos (2004) de "modernosa", na qual há uma acomodação por parte dos docentes. A DC é particularmente vulnerável para ser erroneamente apropriada no ensino desta forma, principalmente porque a sua essência é socializar conhecimentos científicos atualizados para todos. Aqui a importância do professor é evidenciada novamente, como o agente responsável por mediar estes recursos de uma maneira significativa.

Tendo isso em mente, uma possível abordagem a ser considerada seria a de explorar, por meio de análises e discussões, os conteúdos presentes nos documentários, ou seja, as informações que compõem o DDC. Uma abordagem neste viés, transformando o próprio audiovisual em objeto de estudo, poderia auxiliar na desconstrução da ideia de "ciência morta" já discutida aqui, especialmente ao trabalhar com um gênero fílmico no qual muitas produções 
se apropriam do discurso da divulgação científica para disseminar ideias negacionistas, como no caso do terraplanismo. Neste sentido, futuras pesquisas que explorem o uso de DDCs de uma maneira problematizadora e dialógica no ensino podem ampliar e aprofundar as relações de Ciência, Tecnologia e Sociedade na Educação Básica.

Referindo-se à produção de audiovisuais em sala de aula, a terceira competência específica da Base Nacional Comum Curricular (BRASIL, 2017), ao tratar das Ciências da Natureza e suas Tecnologias se refere à importância dos estudantes desenvolverem a sua capacidade de solução de problemas e pensamento crítico sobre a informação que recebem, assim como devem se apropriar da linguagem e método científico, socializando o aprendizado mediante tecnologias e mídias em contextos variados. Tendo isto em mente, os trabalhos de Cazón e Oliveira (2015), assim como Vieira e Ramos (2015), desenvolveram esta socialização por meio de mídias audiovisuais.

Acredita-se que a produção de documentários por estudantes é uma atitude positiva para romper o ensino tradicional/autoritário. Com ampliação e acesso a tecnologias, como o celular e os computadores, a produção de filmes pode ser favorecida (LOPES; PIMENTA, 2017). O espaço escolar permite a realização de eventos como oficinas e feiras científicas, em que as produções poderiam ser socializadas com a comunidade escolar, o que incentiva o espírito artístico, crítico e científico dos estudantes. A investigação de temas polêmicos, como a biotecnologia, é uma excelente alternativa como ponto de partida para estes filmes, pois desafia as visões do senso comum e provoca a busca por um conhecimento interdisciplinar.

Segundo Pozo e Crespo (2009), é justamente uma nova cultura de aprendizagem, na perspectiva construtivista, que pode ajudar a mediar o conhecimento no Ensino de Ciências, pois assim o processo de aprendizado é um meio de transformações e reconstruções e não de acumulação passiva de conhecimentos, contribuindo para o desenvolvimento de uma imagem que represente a ciência de maneira mais fidedigna, como um conhecimento histórico, passível de mudanças e em que a presença de incertezas é algo necessário. Além disso, o construtivismo considera as diferentes formas de construção do conhecimento, que surgem de acordo com mudanças sociais e novas demandas da educação. A mudança nos métodos de ensinoaprendizado é fundamental para que os estudantes possam se conectar, participar e apreciar a cultura, e interpretar de maneira crítica as informações que recebe, especialmente com o desenvolvimento das tecnologias de informação.

E qual a relevância de saber o que outros pesquisadores vêm apontando? Para Arroio (2013), o Ensino das Ciências da Natureza é essencial para a formação de um cidadão crítico e participativo na sociedade, porém apresenta desafios em ser realizado de forma significativa para os estudantes. Sendo assim, é necessário que o profissional da Educação esteja atento às tendências do ensino a fim de superar as barreiras no Ensino de Ciências. Além disso, a constante busca por novas ideias por parte do professor o torna um profissional reflexivo e crítico em relação à sua prática, reposicionando-o do local de aplicador para autor de ideias. Resta enfim observar, assumindo com Arroio (2013), que a aliança entre a prática docente e o conhecimento teórico possibilitam o uso de resultados de outros autores de forma ainda mais significativa para o contexto sociocultural em que estão inseridos.

\section{Considerações finais}

Este artigo de pesquisa revela um panorama significativo sobre estudos que discutem DDC no Ensino de Ciências, proporcionando um espaço para reflexão acerca das potencialidades destes documentários nos contextos escolares. 
Pelas análises, pôde-se observar que o uso desta mídia numa perspectiva dialógica permite uma maior compreensão dos estudantes em relação a conceitos científicos propiciando a construção de conhecimento. Para tanto, o papel do professor é essencial no planejamento e utilização destes recursos na sala de aula, para identificar os conteúdos, promover discussões e contextualizar o que é trabalhado, levando também em consideração o contexto escolar e o local no qual os estudantes estão inseridos.

Neste sentido, implica assumir uma perspectiva discursiva de formação e não capacitação docente para o uso destes recursos audiovisuais. Com bem escreve Orlandi (2017), a formação implica na capacidade de observar, interpretar e compreender a realidade e os papéis nos quais os sujeitos se inserem e exercem na sociedade, para então ser possível a intervenção e modificação de realidades. Enquanto a capacitação é o treinamento para o desempenho, que visa o resultado e não o conhecimento. A interpretação e contextualização de um documentário em sala de aula, por exemplo, é característica da formação de professores. Já a exibição do filme apenas para a ilustração de conceitos pode gerar resultados positivos em avaliações, porém é uma abordagem característica da capacitação de professores.

Pontua-se que uma das contribuições deste estudo para o campo de pesquisa em Educação em Ciências, foi a identificação da carência de investigações sobre o uso de DDCs no Ensino Fundamental, tanto nos Anos Iniciais quanto Anos Finais. Pressupõem-se que essa lacuna esteja relacionada com a ênfase sobre os conteúdos de muitos documentários serem avançados para os estudantes dos anos iniciais; ao grande número de alunos por sala de aula neste nível de ensino, dificultando aprofundamento em debates; pouca infraestrutura para exibição de materiais audiovisuais em escolas públicas; e até mesmo carga horária incompatível com a necessidade para assistir aos documentários durante as aulas. Desta forma, futuras pesquisas nesta área podem contribuir para uma visão mais holística sobre o funcionamento dos documentários ao longo da Educação Básica.

À guisa de conclusão, os documentários são ferramentas de divulgação científica eficientes no sentido de aprimorar os conhecimentos científicos numa prática educativa em sentido construtivo. Poder-se-á concebê-los mais do que ferramentas de ensino, mas como pilares da educação envolvida com a divulgação científica. Indo além, é preciso que sejam incluídos e utilizados de forma contextualizada, problematizada e dialógica aos objetivos do Ensino de Ciências, ou seja, como processo integrativo do ensinar e não como apenas mais uma forma de expor o conteúdo.

\section{Referências}

ANCINE - Agência Nacional do Cinema. Anuário Estatístico do Cinema Brasileiro. Brasília: Agência Nacional de Cinema, 2018.

ARROIO, A. The role of cinema into science education. Problems of education in the 21st century, Siauliai, Lituânia, v. 1, p. 25-30, 2007.

ARROIO, A. O ensino de Ciências da Natureza para uma sociedade contemporânea. In: CARVALHO, A. M. P. Formação de professores: múltiplos enfoques. São Paulo: Sarandi. 2013. p. 165-180. 
BORBA, B. A. Documentários de natureza: um panorama a partir dos estudos culturais. In: SEMINÁRIO BRASILEIRO DE ESTUDOS CULTURAIS E EDUCAÇÃO, 7, 2017, Porto Alegre. Anais [...]. Porto Alegre: UFRGS, 2017. p. 1-14.

BRASIL. Ministério da Educação. Base Nacional Comum Curricular. Brasília: MEC, 2017.

BRASIL. Ministério da Educação. Censo escolar da educação básica 2019: notas estatísticas. Brasília: MEC, 2019.

BRUZZO, C. O documentário em sala de aula. Ciência \& Ensino, Piracicaba, São Paulo, v. 3, n. 1, p. 23-25, 1998.

BUENO, A. J. A; SILVA, S. L. R. O cinema como linguagem no ensino de ciências. Actio: Docência em Ciências, Curitiba, v. 3, n. 2., p. 154-172, 2018.

BUENO, W. C. Comunicação científica e divulgação científica: aproximações e rupturas conceituais. Informação \& Informação, João Pessoa, v. 15, n. 1, p. 1-12, 2010.

CAMARGO, B. V; BARBARÁ, A; BERTOLDO, R. B. A influência de vídeos documentários na divulgação científica de conhecimento sobre a Aids. Psicologia: Reflexão e Crítica, Porto Alegre, v. 21, n. 2, p. 179-185, 2008.

CARVALHO, A. M. P; GIL-PÉREZ, D. Formação de professores de Ciências: tendências e inovações. 10. ed. São Paulo: Cortez, 2011.

CAZÓN. H; OLIVEIRA, O. B. Produção de documentário científico e as relações com o saber. In: ENCONTRO NACIONAL DE PESQUISA EM EDUCAÇÃO EM CIÊNCIAS (ENPEC), 10., 2015, Águas de Lindóia. Anais [...]. Águas de Lindóia: ABRAPEC, 2015.

COUTO, H. H. O. M.; REZENDE FILHO, L. A. Documentário de Divulgação Científica em tempos de redes sociais e cibercultura. In: ENCONTRO NACIONAL DE PESQUISA EM EDUCAÇÃO EM CIÊNCIAS (ENPEC), 8, 2011, Campinas, SP. Anais [...]. Campinas: ABRAPEC, 2011.

CRUZ, A. B.; FERNANDES, G. W. R. Limites e possibilidades sobre o uso do vídeo documentário científico no ensino de Física. In: ENCONTRO NACIONAL DE PESQUISA EM EDUCAÇÃO EM CIÊNCIAS (ENPEC), 9, 2013, Águas de Lindóia, SP. Anais [...]. Campinas: ABRAPEC, 2011. Águas de Lindóia: ABRAPEC, 2013.

CUNHA, M. B; GIORDAN, M. A divulgação científica na sala de aula: implicações de um gênero. In: GIORDAN, M; CUNHA, M. B. Divulgação Científica na sala de aula: perspectivas e possibilidades. Ijuí, RS: Unijuí. 2015. 360p.

DELIZOICOV, D; ANGOTTI, J. A; PERNAMBUCO, Ensino de Ciências: fundamentos e métodos. 5. ed. São Paulo: Cortez. 2018. 288 p. 
FERREIRA, L. N. A; QUEIROZ, S. L. Utilização de textos de divulgação científica em salas de aula de química. In: GIORDAN, M; CUNHA, M. B. Divulgação Científica na sala de aula: perspectivas e possibilidades. Ijuí, RS: Unijuí. 2015. 360p.

FREY, D. "O despertar de uma paixão" e o ensino de cólera e evolução. In: ENCONTRO NACIONAL DE PESQUISA EM EDUCAÇÃO EM CIÊNCIAS (ENPEC), 12, 2019, Natal. Anais[...]. Campinas: ABRAPEC, 2011. Natal: ABRAPEC, 2019.

GIL, A. C. Métodos e técnicas de pesquisa social. 6. ed. São Paulo: Atlas, 2010.

GUEDES, F. A. C.; REIS, R. A.; JOUCOSKI, E. O uso de vídeo de caráter regional como instrumento didático para a educação ambiental. Gaia Scientia, Matinhos, v. 11, n. 3. p. 27-40, 2017.

KEMPER, A. A evolução biológica e as revistas de divulgação científica: potencialidades e limitações para o uso em sala de aula. 2008. Dissertação (Mestrado em Educação) Universidade de Brasília, Brasília, 2008.

LAPRISE, S; WINRICH, C. The impact of science fiction films on student interest in science. Journal of College Science Teaching, Virginia, Estados Unidos da América, v. 40, n. 2, p. 45-49, 2010.

LEISEROWITZ, A. Day After Tomorrow: Study of Climate Change Risk Perception. Environment: science and policy for sustainable development, Philadelphia, Estados Unidos da América, v. 46, n. 9, p. 22-39, 2004.

LEÓN, B. Science on television: the narrative of scientific documentary. Luton England: Pantaneto Press, 2007.

LEÓN, B. Science documentaries and their coordinates. Quaderns del CAC, Catalunha. v. 30, p. 11-18, 2008.

LOPES, P. A; PIMENTA C. C. C. O uso do celular em sala de aula como ferramenta pedagógica: benefícios e desafios. Revista Cadernos de Estudos e Pesquisas na Educação Básica, Recife, v. 3, n. 1, p. 52-66, 2017.

MEDEIROS, T. A; MAIA, E. D. A teoria da evolução: as dificuldades encontradas na relação ensino-aprendizagem. In: ENCONTRO NACIONAL DE PESQUISA EM EDUCAÇÃO EM CIÊNCIAS (ENPEC), 9, 2013, Águas de Lindóia, SP. Anais[...]. Campinas: ABRAPEC, 2011. Águas de Lindóia: ABRAPEC, 2013.

MELO, C. T. V. O documentário como gênero audiovisual. Comunicação \& Informação, Goiás, v. 5, n. 1/2, p. 25-40, 2002.

MOREIRA, I. C.; MASSARANI, L. Aspectos históricos da divulgação científica no Brasil. In: MASSARANI, L; MOREIRA, I. C.; BRITO, F. Ciência e público: caminhos da divulgação científica no Brasil. Rio de Janeiro: UFRJ, Casa da Ciência, 2002. 232 p. 
NICHOLS, B. Introdução ao documentário. Campinas: Papirus, 2005. 270 p.

OLIVEIRA, B. J. Cinema e imaginário científico. História, Ciências, Saúde-Manguinhos, Rio de Janeiro, v. 13, p. 133-150, 2006.

ORLANDI, E. P. A linguagem e seu funcionamento: as formas do discurso. 6. ed. Campinas: Pontes, 2011. 263 p.

ORLANDI, E. P. Análise de discurso: princípios e procedimentos. 11. ed. Campinas: Pontes, 2013. $100 \mathrm{p}$.

ORLANDI, E. P. Educação e sociedade: o discurso pedagógico entre o conhecimento e a informação. Revista Latinoamericana de Estudios del Discurso, v. 16, n. 2, p. 68-80, 2017.

PÊCHEUX, M. O discurso: estrutura ou acontecimento. 6.ed. Campinas: Pontes, 2012. 68 p.

PASSAU, A. S; MELO. W. V; ANDRADE, L; PEREIRA, R. M. M. Fatores que influenciam na utilização de filmes como recurso didático pelos docentes de Ciências. In: ENCONTRO NACIONAL DE PESQUISA EM EDUCAÇÃO EM CIÊNCIAS (ENPEC), VIII, 2011, Campinas, SP. Anais [...]. Campinas: ABRAPEC, 2011.

PEREIRA, J.; COSTA, A. S. C.; MIQUELIN, A.F.; SILVEIRA, R. M. C. F. O estudo da Energia com enfoque CTS, fundamentado no documentário POWER. In: ENCONTRO NACIONAL DE PESQUISA EM EDUCAÇÃO EM CIÊNCIAS (ENPEC), XI, 2017, Florianópolis. Anais [...]. Florianópolis: ABRAPEC, 2017.

POZO, J. I.; CRESPO, M. A. G. A aprendizagem e o ensino de Ciências: do conhecimento cotidiano ao conhecimento científico. 5. ed. Porto Alegre: Artmed, 2009. 296 p.

QUEIROZ, S. L; FERREIRA, L. N. A. Traços de cientificidade, didaticidade e laicidade em artigos da revista 'Ciência Hoje' relacionados à química. Ciência e educação, Bauru, v. 19, n. 4, p. 947-969, 2013

REIS, J. Ponto de vista: José Reis. Entrevista. In: MASSARANI, L; MOREIRA, IC; BRITO, F. Ciência e público: caminhos da divulgação científica no Brasil. Rio de Janeiro: Casa da Ciência/Centro Cultural de Ciência e Tecnologia da UFRJ, 2002. 231 p.

SANT'ANNA, I. M.; SANT'ANNA, V. M. Recursos educacionais para o ensino: quando e por quê? Petrópolis: Vozes, 2004. 120 p.

SANTOS, E. G; FRIEDRICH, S. P. O Cinema na sala de aula. In: GÜLLICH, R. I. C. Didática das Ciências. Curitiba: Appris. 2013. 339 p.

SANTOS, J. N.; GEBARA, M. J. F. Cinema como recurso didático: motivação nas aulas de ensino de Ciências. In: ENCONTRO NACIONAL DE PESQUISA EM EDUCAÇÃO EM CIÊNCIAS (ENPEC), 9, 2013, Águas de Lindóia, SP. Anais [...]. Águas de Lindóia:

ABRAPEC, 2013. 
SANTROCK, J. W. Psicologia educacional. Porto Alegre: McGraw Hill, 2009. 692 p.

SILVA, D. S. F.; FRENEDOZO, R. C. A utilização de filmes na mediação da aprendizagem de temas sobre a aplicação do conhecimento genético no ensino de Biologia. In: ENCONTRO NACIONAL DE PESQUISA EM EDUCAÇÃ̃O EM CIÊNCIAS (ENPEC), 8, 2011, Campinas, SP. Anais [...]. Campinas: ABRAPEC, 2011.

SURMELI, H. Examination the effect of science fiction films on science education students' attitudes towards STS Course. Procedia - Social and Behavioral Sciences, Romênia, v. 47, p. 1012-1016, 2012.

VASCONCELLOS, C. S. Construção do conhecimento em sala de aula. 15. ed. São Paulo: Libertad, 2004. 133 p.

VIEIRA, R. C.; MARTINS, M. R. O uso de vídeos do gênero documentário em aulas de Ciências Naturais: uma janela para o real? In: ENCONTRO NACIONAL DE PESQUISA EM EDUCAÇÃO EM CIÊNCIAS (ENPEC), 11, 2017, Florianópolis. Anais [...]. Florianópolis: ABRAPEC, 2017.

VIEIRA, R. C; RAMOS, M. B. Representações de invertebrados em aulas de Biologia. In: ENCONTRO NACIONAL DE PESQUISA EM EDUCAÇÃO EM CIÊNCIAS (ENPEC), 10, 2015, Águas de Lindóia, SP. Anais [...]. Águas de Lindóia: ABRAPEC, 2015.

XAVIER, J.; GONÇALVES, C. A relação entre a divulgação científica e a escola. Revista Arete: Revista Amazônica de Ensino de Ciências, Manaus, v. 7, n. 14, p. 182-189, 2017.

ZAMBONI, L. M. S. Cientistas, jornalistas e a divulgação científica: subjetividade e heterogeneidade no discurso da divulgação científica. Campinas: Editores Associados, 2001. $167 \mathrm{p}$.

Recebido em maio de 2021.

Aprovado em outubro de 2021. 